\title{
Therapeutic antibody targeting of individual Notch receptors
}

\author{
Yan Wu ${ }^{1 *}$, Carol Cain-Hom ${ }^{2 *}$, Lisa Choy ${ }^{2}$, Thijs J. Hagenbeek ${ }^{2}$, Gladys P. de Leon ${ }^{7}$, Yongmei Chen ${ }^{1}$, David Finkle ${ }^{4}$, \\ Rayna Venook ${ }^{4}$, Xiumin $\mathrm{Wu}^{5}$, John Ridgway ${ }^{5}$, Dorreyah Schahin-Reed ${ }^{6}$, Graham J. Dow ${ }^{2} \dagger$, Amy Shelton $^{2}$, \\ Scott Stawicki ${ }^{1}$, Ryan J. Watts ${ }^{6}$, Jeff Zhang ${ }^{8}$, Robert Choy ${ }^{8}$, Peter Howard ${ }^{8}$, Lisa Kadyk ${ }^{8}$, Minhong Yan ${ }^{5}$, Jiping Zha ${ }^{3}$, \\ Christopher A. Callahan ${ }^{3}$, Sarah G. Hymowitz ${ }^{7} \&$ Christian W. Siebel $^{2}$
}

The four receptors of the Notch family are widely expressed transmembrane proteins that function as key conduits through which mammalian cells communicate to regulate cell fate and growth ${ }^{1,2}$. Ligand binding triggers a conformational change in the receptor negative regulatory region (NRR) that enables ADAM protease cleavage $^{3,4}$ at a juxtamembrane site that otherwise lies buried within the quiescent $\mathrm{NRR}^{5,6}$. Subsequent intramembrane proteolysis catalysed by the $\gamma$-secretase complex liberates the intracellular domain (ICD) to initiate the downstream Notch transcriptional program. Aberrant signalling through each receptor has been linked to numerous diseases, particularly cancer ${ }^{7}$, making the Notch pathway a compelling target for new drugs. Although $\gamma$-secretase inhibitors (GSIs) have progressed into the clinic $^{8}$, GSIs fail to distinguish individual Notch receptors, inhibit other signalling pathways ${ }^{9}$ and cause intestinal toxicity ${ }^{10}$, attributed to dual inhibition of Notch1 and 2 (ref. 11). To elucidate the discrete functions of Notch1 and Notch 2 and develop clinically relevant inhibitors that reduce intestinal toxicity, we used phage display technology to generate highly specialized antibodies that specifically antagonize each receptor paralogue and yet cross-react with the human and mouse sequences, enabling the discrimination of Notch1 versus Notch2 function in human patients and rodent models. Our co-crystal structure shows that the inhibitory mechanism relies on stabilizing NRR quiescence. Selective blocking of Notch1 inhibits tumour growth in pre-clinical models through two mechanisms: inhibition of cancer cell growth and deregulation of angiogenesis. Whereas inhibition of Notch1 plus Notch 2 causes severe intestinal toxicity, inhibition of either receptor alone reduces or avoids this effect, demonstrating a clear advantage over pan-Notch inhibitors. Our studies emphasize the value of paralogue-specific antagonists in dissecting the contributions of distinct Notch receptors to differentiation and disease and reveal the therapeutic promise in targeting Notch1 and Notch2 independently.

To enable independent antagonism of Notch1 and Notch2, we used phage display to generate antibodies targeting the NRRs. Previous studies proposed that antibody targeting of the NRR might stabilize the 'off conformation', and the report of mouse monoclonal antibody antagonists against the human Notch3 NRR supports this approach ${ }^{12}$. As an important advance, each of our synthetic antibodies, anti-NRR1 and anti-NRR2, is a clinically relevant, fully human IgG1 selected to (1) potently inhibit its cognate paralogue but not other Notch receptors, (2) bind the human orthologue for therapeutic targeting, and (3) bind the mouse orthologue for dissecting receptor-specific functions in mouse models. Each antibody bound highly specifically to its cognate receptor but not to any of the other receptors, measured by enzyme-linked immunosorbent assay (ELISA), surface plasmon resonance (SPR) and flow cytometry (Fig. 1a, b and Supplementary Figs 1,2$)$. Each antibody bound with similar high affinities $\left(K_{\mathrm{d}}=1.3-\right.$ $3.1 \mathrm{nM})$ to both the human and mouse sequences of only the targeted NRR (Fig. 1a, b).

We assayed signalling in vitro using a co-culture assay with one cell line expressing the Notch ligand Jagged 1 (Jag1) and a second expressing Notch1 or Notch2. Anti-NRR1 inhibited signalling in the Notch1 cells in a dose-dependent manner. Complete inhibition, equivalent to the background signal seen without induction (-Jag1) or in the presence of a GSI (DAPT), occurred between 80 and $400 \mathrm{ng} \mathrm{ml}^{-1}$ of antibody (Fig. 1c, left). Addition of purified NRR1 but not NRR2 antigen rescued signalling inhibited by anti-NRR1, confirming that inhibition reflected specific binding of anti-NRR1 to NRR1 (Fig. 1c, left). Using Notch2expressing cells to assay anti-NRR2 activity, we observed similarly potent and specific inhibition of Notch2 signalling (Fig. 1c, right). Both antibodies inhibited signalling induced through the ligands Jag1, Jag2, Delta-like1 (Dll1) and Dll4, and thus inhibition occurs irrespective of the ligand (Supplementary Fig. 3).

To determine whether anti-NRR1 and anti-NRR2 function as receptor-specific inhibitors in vivo, we investigated the development of $\mathrm{T}$ cells and splenic marginal zone B (MZB) cells because each depends distinctly on Notch1 or Notch2, respectively ${ }^{13-15}$. Treating mice with anti-NRR1, but not anti-NRR2, significantly reduced thymus weights and cellularity (Supplementary Fig. 4). Relative to the anti-gD control $(77.5 \%)$, anti-NRR1 dramatically reduced the $\mathrm{CD}^{+} / \mathrm{CD}^{+}$population $(5.9 \%)$ whereas anti-NRR2 did not $(80 \%)$ (Fig. 1d). In contrast, treatment with anti-NRR2 nearly eliminated $\mathrm{CD} 21^{\mathrm{hi}} \mathrm{CD} 23^{\mathrm{lo} /-} \mathrm{MZB}$ cells, reducing the population more than lymphotoxin- $\beta$ receptor (LT $\beta R$ )-Fc fusion protein ${ }^{16}$, a positive control (Fig. 1e). Anti-NRR1 did not significantly reduce the MZB population and thus appears not to affect Notch2 signalling, consistent with in vitro data (Supplementary Fig. 5). Our results demonstrate that anti-NRR1 and anti-NRR2 are potent paralogue-specific inhibitors of signalling from Notch1 and Notch2, respectively.

To understand the molecular basis of anti-NRR1 antagonistic activity, we determined the $2.2 \AA$ crystal structure of the antibody Fab fragment bound to human NRR1 (Fig. 1f, g and Supplementary Table 1). The NRR consists of three Lin-Notch repeats (LNRs) juxtaposed with the heterodimerization (HD) domain, in turn comprised of amino- and carboxy-terminal subdomains. Our structure of NRR1 

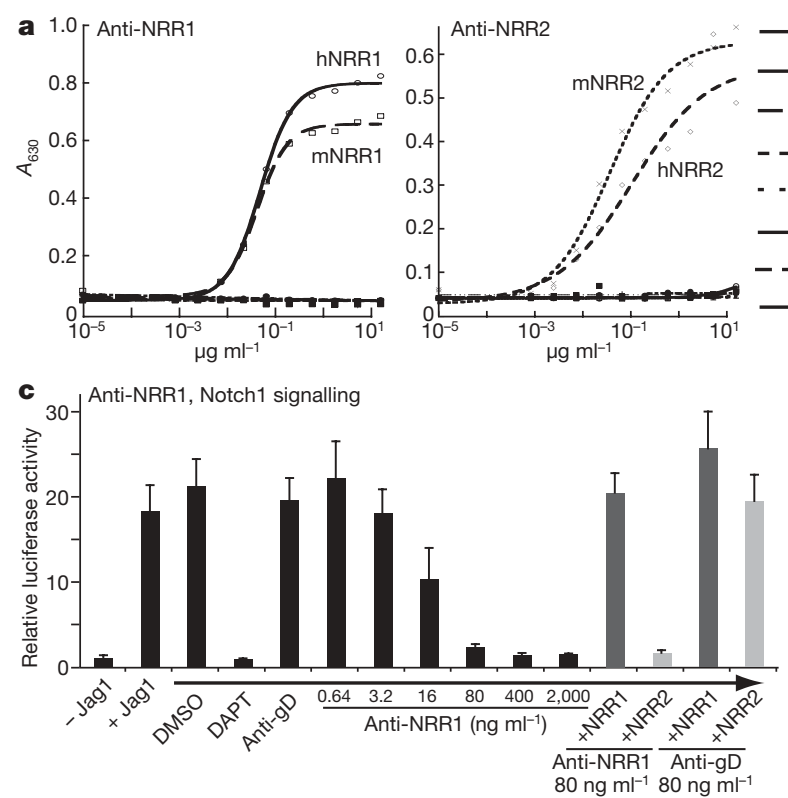

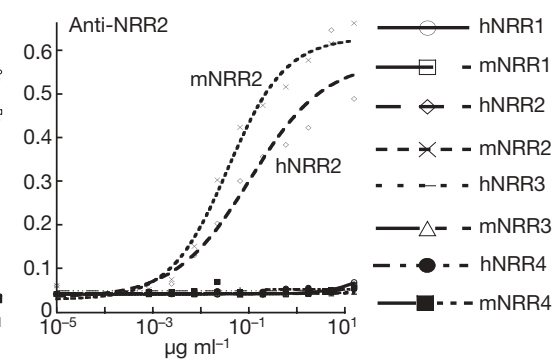

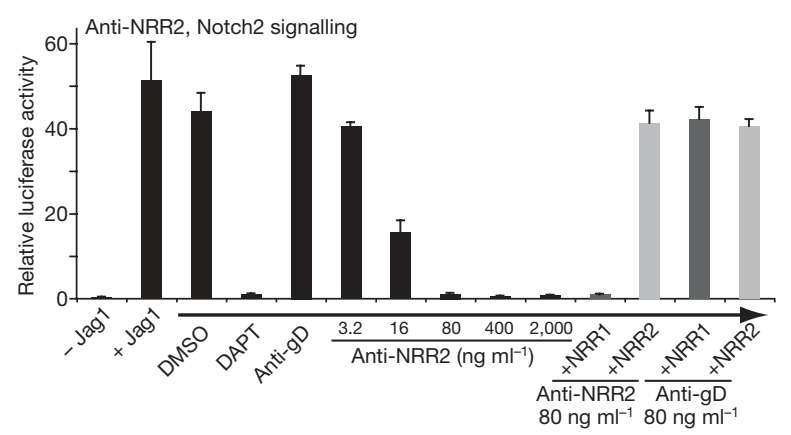

d
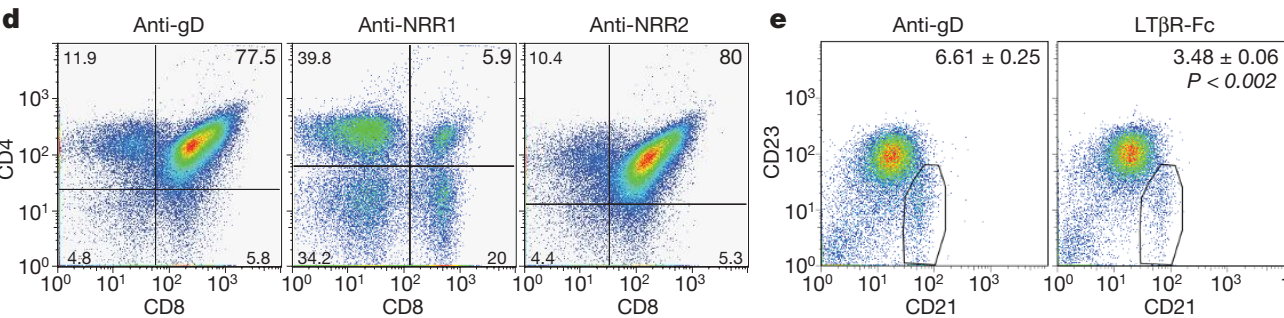

Anti-NRR1

\begin{tabular}{ccc}
$\begin{array}{c}k_{\text {on }} \\
\left(\mathrm{M}^{-1} \mathrm{~s}^{-1}\right)\end{array}$ & $\begin{array}{c}k_{\text {off }} \\
\left(\mathrm{s}^{-1}\right)\end{array}$ & $\begin{array}{c}K_{\mathrm{d}} \\
(\mathrm{M})\end{array}$ \\
\hline $\mathrm{ND}$ & $\mathrm{ND}$ & $\mathrm{ND}$ \\
$\mathrm{ND}$ & $\mathrm{ND}$ & $\mathrm{ND}$ \\
& & \\
$7.9 \times 10^{6}$ & $9.9 \times 10^{-3}$ & $1.3 \times 10^{-9}$ \\
$8.3 \times 10^{6}$ & $1.6 \times 10^{-2}$ & $1.9 \times 10^{-9}$
\end{tabular}

$\mathbf{f}$

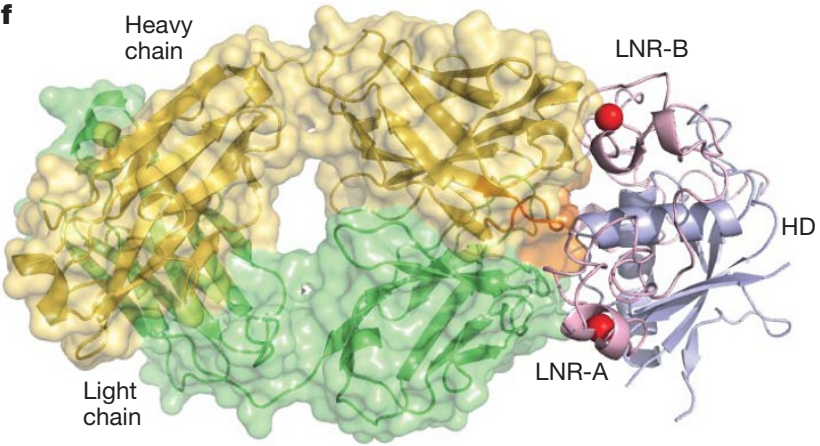

Figure 1 | Anti-NRR1 and anti-NRR2 specifically antagonize their cognate receptors. a, ELISA measuring antibody binding to purified NRR protein fragments from each of the human $(\mathrm{h})$ and murine $(\mathrm{m})$ Notch receptors. b, SPR binding constants; ND, not detectable. c, Co-culture assays of Notch1 (left) or Notch2 (right) signalling, induced with Jag1-expressing cells (+ Jag1). -Jag1, control for no induction; DMSO, dimethyl sulfoxide alone; DAPT, 5 $\mu \mathrm{M}$ in DMSO; anti-gD, isotype control antibody, $2,000 \mathrm{ng} \mathrm{ml}^{-1}$; the last four assays in each panel included $80 \mathrm{ng} \mathrm{ml}^{-1}$ of the indicated antibody plus purified NRR1 or NRR2. Values reflect Notch reporter gene signalling relative to control reporter, normalized to the DAPT values (mean \pm coefficient of variation (CV), $n=5-6)$. d, e, Anti-NRR1 and anti-NRR2 function as receptor-specific inhibitors in vivo. Thymus or spleen cells from mice treated with the indicated reagents were harvested for flow cytometry of $\mathrm{CD} 4^{+} / \mathrm{CD}^{+}$

in complex with anti-NRR1 seems very similar to the previously described compact, autoinhibited NRR structures ${ }^{5,6}$. The epitope is dispersed across the NRR face, spanning residues in LNR-A, LNR-B and HD-C, consistent with domain swap experiments (Supplementary Fig. 6). Despite the $\sim 45 \%$ sequence identity between NRR1 and NRR2, only $29 \%$ of the epitope residues are identical, revealing the basis of anti-NRR1 specificity for Notch1 over Notch2 (Fig. 1g and Supplementary Fig. 7). The Fab heavy chain contacts LNR-B, the final helix in the HD-C domain, and the periphery of LNR-A, whereas the light chain contacts the connecting loop before the final helix in the

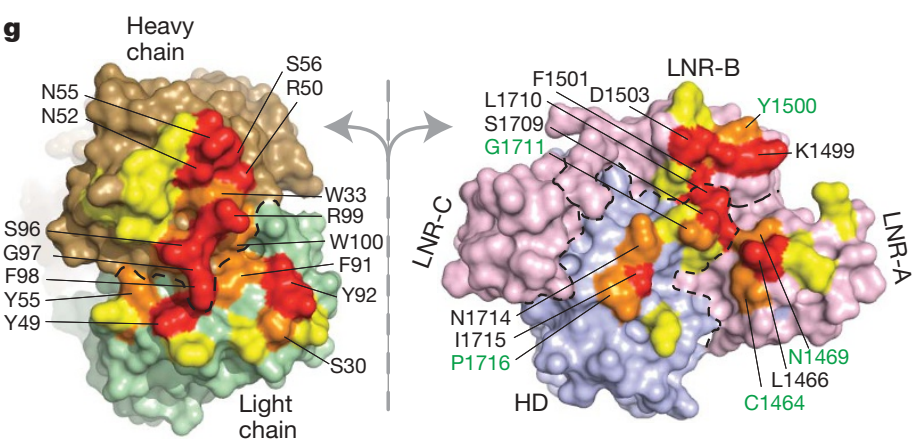

T cells (d) or splenic MZB cells (e). Numbers represent the mean percentages \pm s.d. $(n=3)$ of cells within the boxed gates; representative dot plots are shown. $f$, Side-view of the $2.2 \AA$ structure of the anti-NRR 1 Fab-NRR1 complex showing anti-NRR1 binding across the face of NRR1, bridging the LNR and HD domains; LNR-C is hidden from view behind the complex. The Fab heavy and light chains are yellow and green, respectively, whereas the LNR and HD subdomains are pink and blue, respectively; heavy chain CDR3 residues that bury surface area upon binding NRR1 are orange. g, Open-book view of the interface between anti-NRR1 Fab (left) and human NRR1 (right). Residue colouring symbolizes the extent to which the solvent accessible surface area is buried by complex formation (25-49\%, yellow; $50-75 \%$, orange; $>75 \%$, red). Residues buried by $\geq 50 \%$ are labelled, with identical residues in the Notch1 and Notch2 NRRs in green.

HD domain and LNR-A. CDR H3 nestles into the interface between LNR-B and HD, with R99 from H3 packing against L1710 from the HD domain and forming a hydrogen bond to the backbone carbonyl of LNR-B residue F1501. This structure suggests an inhibitory mechanism in which anti-NRR1 functions as a molecular clamp between the LNR-AB region and the HD domain, stabilizing the autoinhibited NRR1 and interfering with the conformational changes required for receptor activation.

To determine whether anti-NRR1 can directly inhibit growth of cancer cells, we initially focused on T-cell acute lymphoblastic 

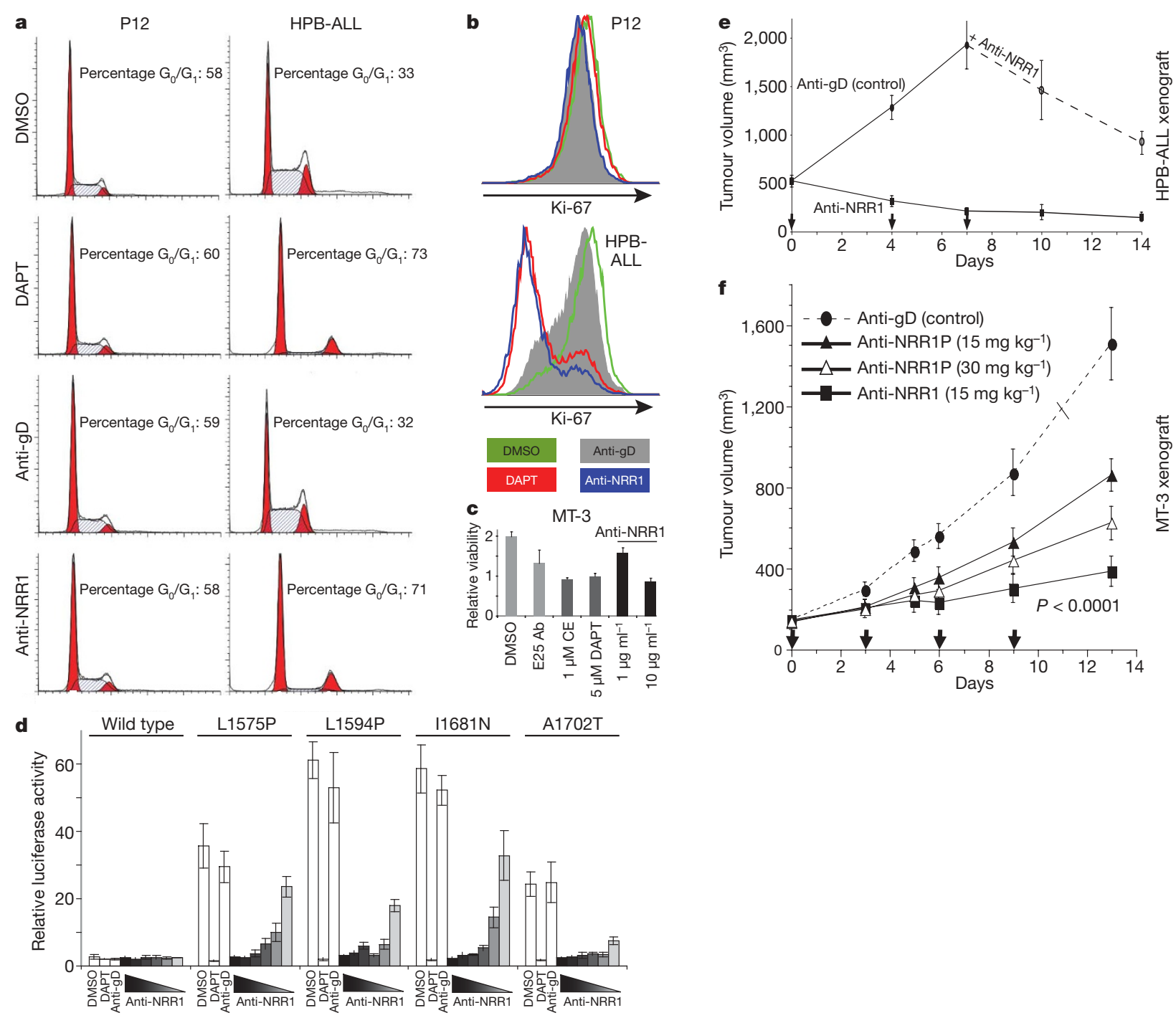

Figure 2 | Anti-NRR1 inhibits growth of Notch1-driven cancer cells and blocks signalling through mutationally destabilized NRRs. a, b, Anti-NRR1 causes a $\mathrm{G}_{0} / \mathrm{G}_{1}$ block of T-ALL cell cycling and proliferation. P12-Ichikawa (control, resistant to GSIs) and HPB-ALL (sensitive to GSIs) cells were treated with the indicated reagents, and cell cycling (DNA content) (a) or proliferation (Ki-67) (b) were assessed. c, Anti-NRR1 decreases viability of MT-3 colon cancer cells. MT-3 cells were treated with the indicated reagents $\left(\mathrm{E} 25,10 \mu \mathrm{g} \mathrm{ml}^{-1}\right.$ isotype control antibody; CE, compound E GSI), and viability was assessed by measuring ATP levels (normalized to the DAPT cultures; mean $\pm \mathrm{CV}, n=8$ ). d, Co-culture assays demonstrating that

leukaemia (T-ALL). Over half of T-ALL patients carry activating Notch1 mutations, the most frequent class comprised of amino acid substitutions in the NRR that destabilize the autoinhibited conformation and activate ligand-independent signalling ${ }^{17,18}$. Screens measuring T-ALL cell line growth have identified several that are sensitive to GSI treatment ${ }^{17}$. One such cell line, HPB-ALL, expresses Notch1 with both an activating mutation (L1575P) in the NRR and a PEST domain truncation, which prolongs signalling ${ }^{17}$. As a control T-ALL line expected to be resistant to GSIs (and thus anti-NRR1), we examined P12-Ichikawa (P12) cells. Although P12 cells express Notch1 that is constitutively activated by a 12 amino acid insertion between the NRR and the transmembrane domain, they are resistant to GSIs because they have acquired additional genetic changes that bypass the need for Notch signalling ${ }^{17,19}$. Treatment of HPB-ALL cells with DAPT or anti-NRR1 significantly increased the percentage of cells in the $G_{0} / G_{1}$ phases of the cell cycle and reduced staining for the proliferation marker Ki-67 (also known as Mki67; Fig. 2a, b).
anti-NRR1 inhibits signalling of mutationally-activated Notch1 receptors. NRR1 point mutations listed at top. Anti-NRR1, fivefold serial dilutions from 50 to $0.016 \mu \mathrm{g} \mathrm{ml}^{-1}$ (mean $\left.\pm \mathrm{CV}, n=4\right)$. e, f, Effects of anti-NRR1 in HPB-ALL and MT-3 xenografts. Mice carrying established tumours were dosed (arrows) with the indicated antibodies (anti-NRR1P, low affinity parent of anti-NRR1 before affinity maturation) and tumour volumes were measured (mean \pm s.e.m.). In (e), mice in the anti-gD group were switched on day 7 to anti-NRR1 dosing (days seven and 10). $n=15$ for anti-gD; $n=17$ for anti-NRR1. In $\mathbf{f}, n=9$.

Both drugs also decreased HPB-ALL cell size and increased apoptosis (Supplementary Figs 8 and 9), both effects correlating with inhibition of Notch1 activation (Supplementary Fig. 10). As expected, neither drug affected the GSI-resistant P12 cells. These results demonstrate that anti-NRR1 can directly inhibit T-ALL cell growth in vitro.

These effects of anti-NRR1 on HPB-ALL cells also suggested that anti-NRR1 inhibits signalling through Notch1 with a NRR point mutation. Given that T-ALL NRR mutations lie in and destabilize the very domain that anti-NRR1 targets, we tested whether different NRR mutations affected anti-NRR1 antagonism. We chose L1594P and L1575P, two of the most common T-ALL mutations, as well as I $1681 \mathrm{~N}$, one of the strongest activating mutations ${ }^{18}$. In a reporter assay, anti-NRR1 inhibited signalling activated by each of these three NRR mutations (Fig. 2d) as well as a PEST domain truncation, representative of the other common cluster of T-ALL mutations (Supplementary Fig. 11) ${ }^{17}$. Also, anti-NRR1 binding to the NRR was not affected by another activating NRR mutation (L1597H), as 
judged by SPR and ELISA assays (data not shown). Together with the observation that none of the known T-ALL NRR point mutations fall within the anti-NRR1 epitope (Supplementary Fig. 12), these results suggest that the ability of anti-NRR1 to inhibit mutant signalling will apply to the majority of the known NRR1 point mutations in T-ALL.

To identify additional oncology indications for anti-NRR1, we screened a panel of $\sim 45$ cancer cell lines for anti-NRR1 sensitivity and identified a human colon cancer line, MT-3. Anti-NRR1 and GSIs decreased MT-3 viability in a dose-dependent and ligandindependent manner (Fig. 2c) that correlated with decreases in ICD levels and target gene expression (data not shown). This ligandindependence suggested that MT-3 cells have an endogenous mechanism for activating Notch1 signalling. Sequencing the NRR and PEST domain exons revealed a single point mutation, A1702T, at the same position as A1702P, a known activating mutation in T-ALL ${ }^{17}$. A1702T activated Notch1 signalling independent of ligand and to a similar extent as L1575P (Fig. 2d). Thus, MT-3 growth appears at least partly driven by Notch1 mutational activation.

We used xenograft models to examine the ability of anti-NRR1 to inhibit tumour growth in vivo. In the HBP-ALL model, anti-NRR1 caused regression of well-established tumours (Fig. 2e). In contrast, tumours from mice in the anti-gD control group grew rapidly; when these animals were switched to dosing with anti-NRR1 on day seven, we again observed tumour regression, particularly notable given the large initial tumour volume. In the MT-3 colon cancer model, antiNRR1 also clearly slowed tumour growth (Fig. 2f and Supplementary Fig. 13). Inhibition depended on antibody affinity, as anti-NRR1P, the parent antibody of anti-NRR1 before affinity maturation $\left(K_{\mathrm{d}}\right.$ approximately $200 \mathrm{nM}$ compared to $3 \mathrm{nM}$ for anti-NRR1), did not inhibit tumour growth as strongly as anti-NRR1 (Fig. 2f). These results establish that anti-NRR1 can inhibit the growth of Notch1dependent tumours in vivo.

Signalling induced by Dll4 through Notch1 and perhaps Notch4 plays a key role in angiogenesis by regulating endothelial cell fate choice $^{20}$. We found that anti-NRR1, like a GSI and anti-Dll4 antagonist, affected lumen-like sprouting from human umbilical vein endothelial cells (HUVECs) (Supplementary Fig. 14) ${ }^{21}$. Likewise, systemic delivery of anti-NRR1 dramatically disrupted retinal vasculature development in neonate mice, generating a dense, compact vascular network (Fig. 3a) correlating with increased proliferation (data not shown). These observations mimic those found following inhibition of Dll4 or $\gamma$-secretase using this same model ${ }^{21}$ and are consistent with results from the mouse corneal pocket assay (data not shown). These anti-angiogenic effects resulted from specific blocking of Notch1 (as opposed to the Notch1 and Notch4 inhibition expected from a GSI), indicating that (1) Notch1 inhibition alone is sufficient and (2) Notch4 inhibition is not necessary to disrupt mammalian angiogenesis.

To determine whether anti-NRR1 is sufficient to inhibit tumour growth through an anti-angiogenic mechanism, we tested mouse xenograft models using the Calu- 6 and HM7 cell lines, chosen because their growth is sensitive to anti-angiogenic reagents in vivo ${ }^{21}$ but not to Notch inhibition in vitro (data not shown). In the Calu-6 model, antiNRR1 caused a decrease in tumour volume, similar to that observed following anti-VEGF treatment (Fig. 3b). We also observed growth inhibition by anti-NRR1 in the aggressively growing HM7 model (Fig. 3d, e). Consistent with reports that selective blocking of Dll4 (refs 21,22 ) increases tumour CD31 staining and generates poorly functioning tumour vasculature, anti-NRR1 increased CD31 staining in Calu-6 tumour sections (Fig. 3c and Supplementary Fig. 15). Taken together, our results indicate that the anti-tumour effects exerted by anti-NRR1 in these models probably reflect a disruption of tumour angiogenesis.

A hurdle to the therapeutic application of pan-Notch inhibitors has been toxicity in the intestinal crypt marked by a decrease of proliferative cells and an increase of secretory goblet cells ${ }^{10}$. However, genetic disruption of Notch1 or Notch2 suggested that this
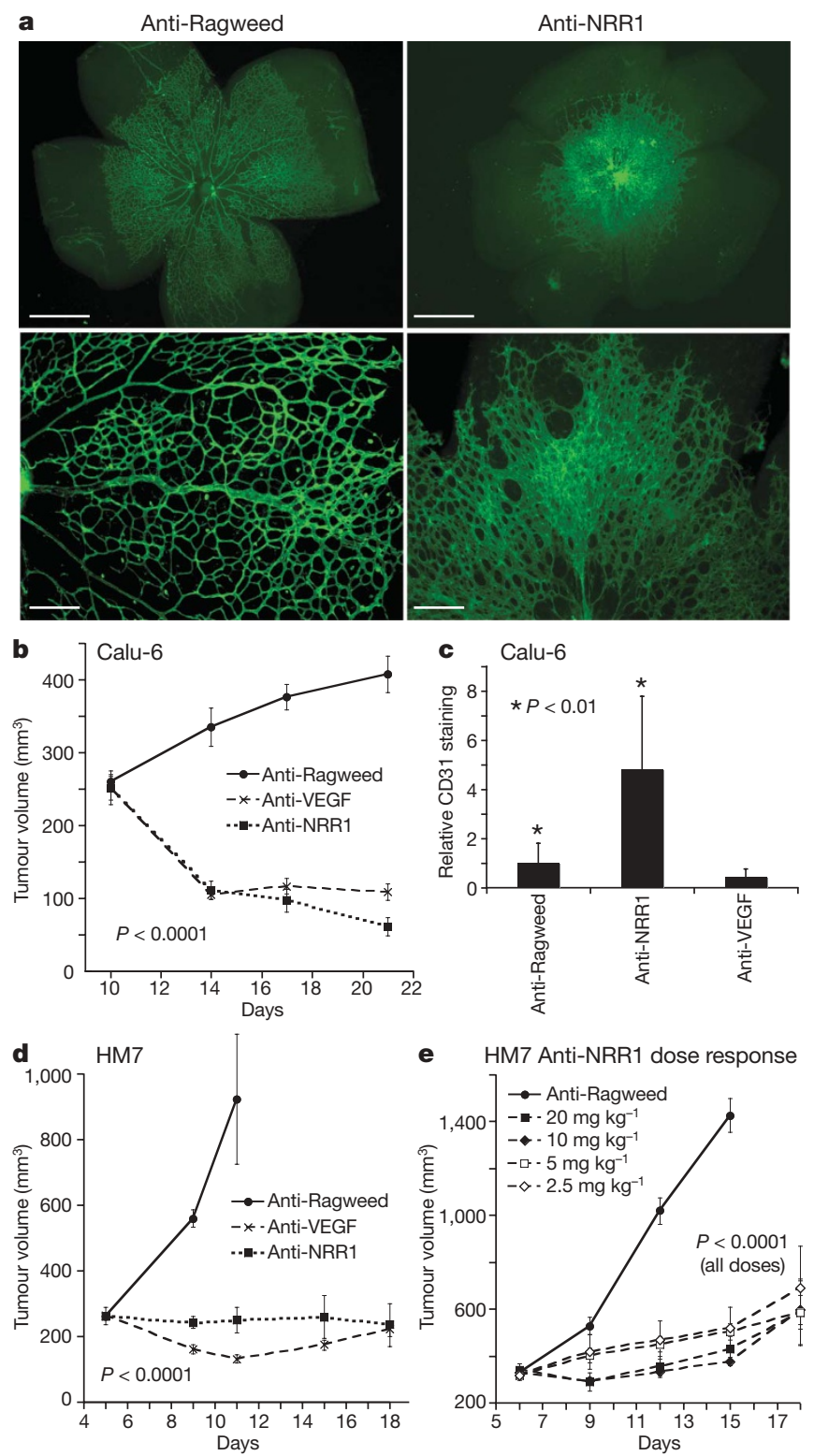

Figure 3 | Anti-NRR1 is an anti-angiogenic agent that inhibits tumour growth. a, Mouse neonate retinal assay for endothelial cell sprouting and angiogenesis. Retinal vasculature from mouse neonates treated with the indicated antibodies was visualized following isolectin perfusion. Top panels, scale bar $=1 \mathrm{~mm}$. Bottom panels, scale bar $=0.2 \mathrm{~mm}$. b, d, e, Graphs for human tumour xenograft models (Calu-6, human anaplastic carcinoma, probably lung; HM7, human colon carcinoma) showing tumour volume following dosing twice per week with the indicated antibodies (mean \pm s.e.m., $n=10$ in $\mathbf{b}, \mathrm{d} ; n=5$ in e; $P$ values for anti-Ragweed vs anti-NRR1). AntiNRR1 at $20 \mathrm{mg} \mathrm{kg}^{-1}$ except where indicated otherwise. c, Quantification of endothelial cell density. Relative anti-CD31 staining was used to score for endothelial cells in tumour sections from the model in (b) (normalized to the anti-Ragweed control; mean \pm s.d.; $n=8$ image fields).

goblet cell metaplasia required inhibition of both receptors ${ }^{11}$, as would be expected following treatment with GSIs but not receptorspecific inhibitors. We found that mice treated with either antiNRR1 or anti-NRR2 maintained weight, but mice treated with anti-NRR1 plus anti-NRR2 lost nearly $20 \%$ of their body weight within 6 days (Fig. 4a). Consistent with previously reported effects of GSIs ${ }^{10}$, intestinal crypts from mice treated with both antibodies showed severe goblet cell metaplasia (Fig. 4b). In contrast, antiNRR2 alone did not detectably affect intestinal morphology or expression of Hes1, a marker of pathway activity. Surprisingly, we found that Notch1 inhibition alone was sufficient to induce some 

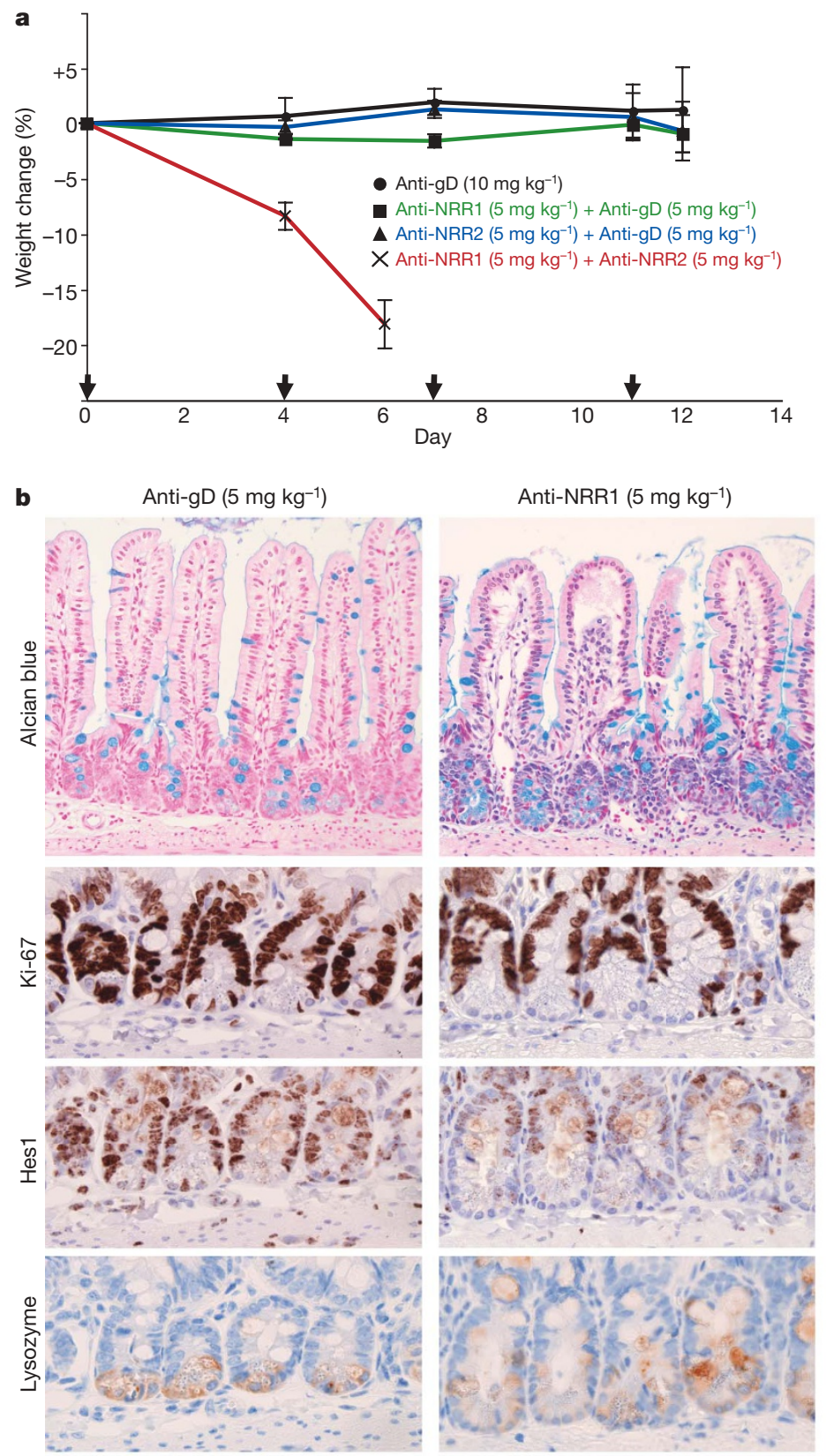

Figure 4 | Selective antibody blocking of Notch1 or Notch2 avoids severe goblet cell metaplasia associated with pan-Notch inhibition. a, Change in total body weight (mean \pm s.d., $n=3$ ) in adult mice dosed (arrows) with the indicated antibodies. b, Immunohistochemical analyses of small intestines, using Alcian blue for mucin to mark secretory goblet cells, anti-Ki-67

goblet cell metaplasia; however, this effect was mild relative to that observed following dual inhibition of Notch1 and Notch2 (Fig. 4b, c). Our results indicate that Notch1 and Notch2 function redundantly in intestinal cell differentiation, although inhibition of Notch1 but not Notch2 is sufficient to reveal a partial phenotype. In reducing or avoiding the goblet cell metaplasia that is a hallmark of a general Notch block, our receptor-specific inhibitors represent a clear breakthrough over existing pan-Notch inhibitors such as GSIs.

Anti-NRR1 and anti-NRR2 stand among the strongest therapeutic candidates for treating indications linked to aberrant Notch signalling, particularly in cancer, immunology and regenerative medicine. Compared to pan-Notch inhibitors such as GSIs or stapled peptides ${ }^{23}$, our fully human antibodies offer the advantages of an improved safety profile, paralogue-specific inhibition and a clinically established drug format. Anti-NRR1 holds the promise of simultaneously targeting cancers by directly inhibiting cancer cell growth and disrupting

\begin{tabular}{c|c|c|c} 
Anti-gD & Anti-NRR1 & Anti-NRR2 & $\begin{array}{c}\text { Anti-NRR1 } \\
+ \\
\text { Anti-NRR2 }\end{array}$ \\
\hline 69 & 52 & 65 & 35
\end{tabular}

.

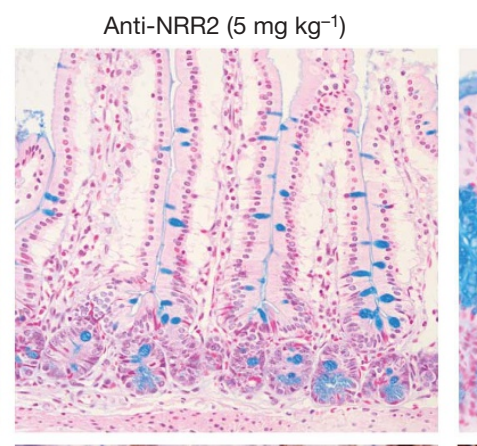

Anti-NRR1 $\left(2.5 \mathrm{mg} \mathrm{kg}^{-1}\right)$

Anti-NRR2 $\stackrel{+}{\left(2.5 \mathrm{mg} \mathrm{kg}^{-1}\right)}$
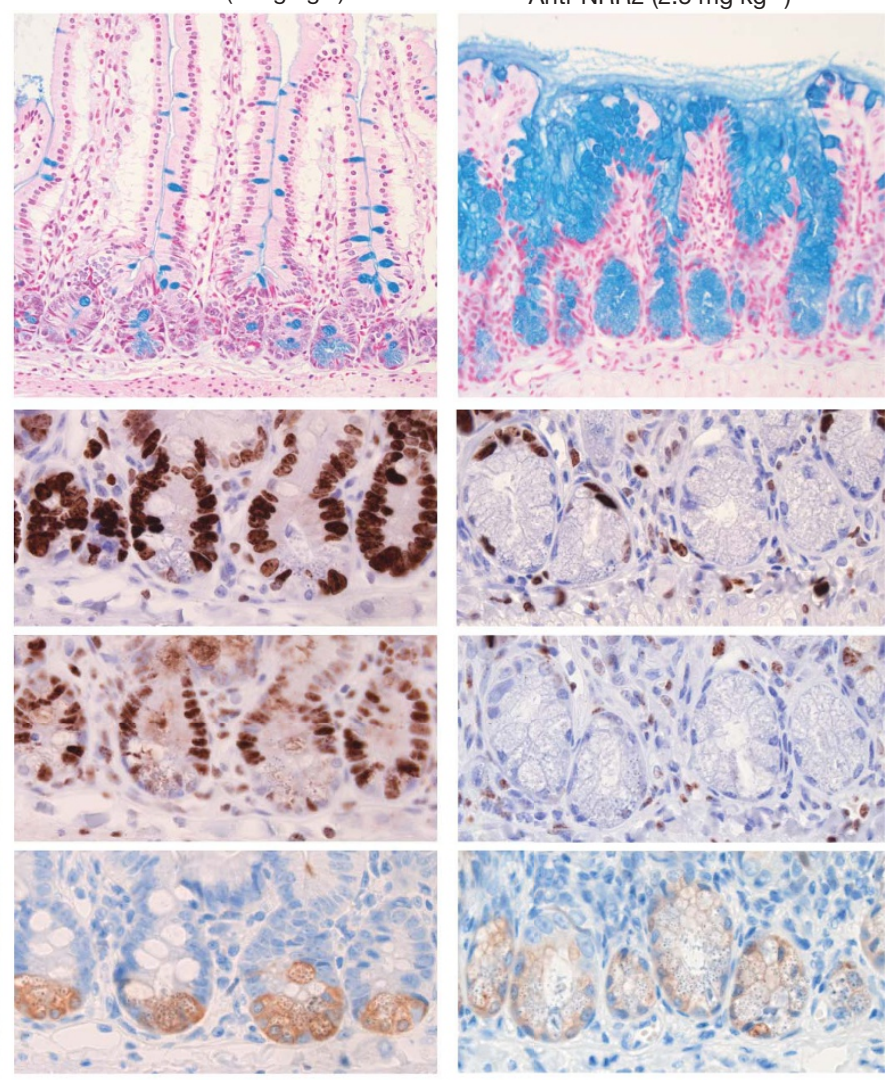

staining for proliferation, anti-Hes1 staining for expression of a Notch pathway target, and lysozyme for Paneth cells. Mice were dosed as in (a) at the indicated concentrations, and tissues were harvested on day 12.

c, Quantification of Ki-67 staining.

tumour angiogenesis. As anti-DLL4 blocking antibodies are entering the clinic because of anti-angiogenic effects, our Notch1 inhibitor may also directly affect tumour cell viability in Notch1-driven cancers and blocks both ligand-dependent and -independent activation. Similarly, Notch 2 has been implicated in many cancers ${ }^{7,24}$, and anti-NRR2 stands as a candidate for treating melanomas ${ }^{25-28}$ and some B-cell leukaemias $^{29,30}$, both linked to the Notch 2 gene by amplification, overexpression or mutation. Our characterizations of anti-NRR1 and anti-NRR2 make a compelling case for adding these Notch receptor-specific antibodies to the arsenal of cancer therapeutics.

\section{METHODS SUMMARY}

Human phage libraries with diversities in the $\mathrm{H} 1, \mathrm{H} 2, \mathrm{H} 3$ and $\mathrm{L} 3$ regions were used for panning. Fab fragments were identified by ELISA/DNA sequencing and reformatted to express IgGs. NRR proteins were purified following expression in mammalian or insect cells. A BIAcore-3000 instrument was used to determine 
binding affinities. Co-culture assays used NIH-3T3 cells stably transfected with Jag1 plus NIH-3T3 cells stably transfected with Notch1 (or transiently transfected with mutant Notch1 expression plasmids; the Notch2 assay used U87MG cells) and transiently co-transfected with a TP-1 (Notch responsive promoter) firefly luciferase reporter and a constitutively expressed Renilla luciferase reporter. T and MZB cell development were analysed by flow cytometry with anti-CD8-phycoerythrin (PE)-Cy5 and anti-CD4-allophycocyanin (APC) or anti-B220-APC, anti-CD5-peridinin chlorophyll protein (PerCP), anti-CD23$\mathrm{PE}$ and anti-CD21-fluorescein (FITC), respectively. The NRR1-Fab structure was solved by molecular replacement to $2.2 \AA$ and refined to an $R$ and $R_{\text {free }}$ of 22.2 and $27.2 \%$, respectively. For cycling, DNA content was determined in 7-8day cultures by flow cytometry after propidium iodide staining and analysed using ModFit. Proliferation was measured by flow cytometry using anti-Ki-67FITC. MT-3 viability was assessed after 1 week using CellTiter-Glo (Promega). Xenografted tumour cells were implanted in the flank of immunocompromised mice. Mice were dosed intraperitoneally twice per week. Tumour angiogenesis was examined with anti-CD31, normalized to total cell number using DAPI. Retinal angiogenesis used CD1 neonates, injected intraperitoneally 1 and 3 days after birth, with retinas analysed 2 days later using biotinylated isolectin B4 to visualize vasculature. Intestinal studies used 12 -week-old $\mathrm{BALB} / \mathrm{c}$ mice. Histochemical identification of intestinal cell types used Alcian blue Proliferation was assessed using anti-Ki-67. Areas of $\geq 100,000 \mu \mathrm{m}^{2}$, containing $\geq 1,000$ crypt cells, were analysed for the percentages of Ki-67-positive epithelial cells. Notch activity and Paneth cells were visualized using anti-Hes1 and antilysozyme, respectively.

Full Methods and any associated references are available in the online version of the paper at www.nature.com/nature.

\section{Received 30 June 2009; accepted 28 January 2010.}

1. Aster, J. C., Pear, W. S. \& Blacklow, S. C. Notch signaling in leukemia. Annu. Rev. Path. 3, 587-613 (2008)

2. Kopan, R. \& Ilagan, M. X. G. The canonical Notch signaling pathway: unfolding the activation mechanism. Cell 137, 216-233 (2009).

3. Mumm, J. S. et al. A ligand-induced extracellular cleavage regulates $\gamma$-secretaselike proteolytic activation of Notch1. Mol. Cell 5, 197-206 (2000).

4. Brou, C. et al. A novel proteolytic cleavage involved in Notch signaling: the role of the disintegrin-metalloprotease TACE. Mol. Cell 5, 207-216 (2000).

5. Gordon, W. R. et al. Structural basis for autoinhibition of Notch. Nature Struct. Mol. Biol. 14, 295-300 (2007)

6. Gordon, W. R. et al. Structure of the Notch1-negative regulatory region: implications for normal activation and pathogenic signaling in T-ALL. Blood 113, 4381-4390 (2009)

7. Koch, U. \& Radtke, F. Notch and cancer: a double-edged sword. Cell. Mol. Life Sci. 64, 2746-2762 (2007).

8. Shih, I.-M. \& Wang, T.-L. Notch signaling, $\gamma$-secretase inhibitors, and cancer therapy. Cancer Res. 67, 1879-1882 (2007).

9. Beel, A. J. \& Sanders, C. Substrate specificity of $\gamma$-secretase and other intramembrane proteases. Cell. Mol. Life Sci. 65, 1311-1334 (2008).

10. van $\mathrm{Es}, \mathrm{J}$. H. et al. Notch/ $\gamma$-secretase inhibition turns proliferative cells in intestinal crypts and adenomas into goblet cells. Nature 435, 959-963 (2005).

11. Riccio, O. et al. Loss of intestinal crypt progenitor cells owing to inactivation of both Notch1 and Notch2 is accompanied by derepression of CDK inhibitors p27Kip1 and p57Kip2. EMBO Rep. 9, 377-383 (2008).

12. Li, K. et al. Modulation of Notch signaling by antibodies specific for the extracellular negative regulatory region of Notch3. J. Biol. Chem. 283, 8046-8054 (2008).

13. Saito, T. et al. Notch2 is preferentially expressed in mature B cells and indispensable for marginal zone B lineage development. Immunity 18, 675-685 (2003).

14. Radtke, F. et al. Deficient T cell fate specification in mice with an induced inactivation of Notch1. Immunity 10, 547-558 (1999).

15. Witt, C. M., Won, W.-J., Hurez, V. \& Klug, C. A. Notch2 haploinsufficiency results in diminished B1 B cells and a severe reduction in marginal zone B cells. J. Immunol. 171, 2783-2788 (2003).

16. Ettinger, R., Browning, J. L., Michie, S. A., van Ewijk, W. \& McDevitt, H. O. Disrupted splenic architecture, but normal lymph node development in mice expressing a soluble lymphotoxin- $\beta$ receptor-lgG1 fusion protein. Proc. Natl Acad. Sci. USA 93, 13102-13107 (1996).
17. Weng, A. P. et al. Activating mutations of $\mathrm{NOTCH} 1$ in human $\mathrm{T}$ cell acute lymphoblastic leukemia. Science 306, 269-271 (2004).

18. Malecki, M. J. et al. Leukemia-associated mutations within the NOTCH1 heterodimerization domain fall into at least two distinct mechanistic classes. Mol. Cell. Biol. 26, 4642-4651 (2006).

19. Palomero, T. et al. Mutational loss of PTEN induces resistance to NOTCH1 inhibition in T-cell leukemia. Nature Med. 13, 1203-1210 (2007).

20. Phng, L. K. \& Gerhardt, H. Angiogenesis: a team effort coordinated by Notch. Dev. Cell 16, 196-208 (2009).

21. Ridgway, J. et al. Inhibition of DII4 signalling inhibits tumour growth by deregulating angiogenesis. Nature 444, 1083-1087 (2006).

22. Noguera-Troise, I. et al. Blockade of DII4 inhibits tumour growth by promoting non-productive angiogenesis. Nature 444, 1032-1037 (2006).

23. Moellering, R. E. et al. Direct inhibition of the NOTCH transcription factor complex. Nature 462, 182-188 (2009).

24. Leong, K. G. \& Karsan, A. Recent insights into the role of Notch signaling in tumorigenesis. Blood 107, 2223-2233 (2006).

25. Jönsson, G. et al. Genomic profiling of malignant melanoma using tiling-resolution array CGH. Oncogene 26, 4738-4748 (2007)

26. Hoek, K. et al. Expression profiling reveals novel pathways in the transformation of melanocytes to melanomas. Cancer Res. 64, 5270-5282 (2004).

27. Massi, D. et al. Evidence for differential expression of Notch receptors and their ligands in melanocytic nevi and cutaneous malignant melanoma. Mod. Pathol. 19, 246-254 (2005)

28. Qin, J.-Z. et al. p53-independent NOXA induction overcomes apoptotic resistance of malignant melanomas. Mol. Cancer Ther. 3, 895-902 (2004).

29. Lee, S.-y. et al. Gain-of-function mutations and copy number increases of Notch2 in diffuse large B-cell lymphoma. Cancer Sci. 100, 920-926 (2009).

30. Trøen, G. et al. NOTCH2 mutations in marginal zone lymphoma. Haematologica 93 , 1107-1109 (2008)

Supplementary Information is linked to the online version of the paper at www.nature.com/nature.

Acknowledgements We acknowledge the Notch scientists at Genentech and Exelixis for support throughout this project. In particular, we thank the following contributors at Exelixis: S.-H. Lin, L. Doukhan, S. Weiss, N. Benin and R. Mercer for protein production, purification and analysis, R. Funke for cloning and sequencing and D. Buckley and J. Greve for scientific discussions and guidance. We thank the Genentech protein expression group, R. Vij and J.-A. Hongo for help with antibody characterization, F. Bazan and C. Sanchez-Irizarry for stimulating discussions and critically reading the manuscript, J. Eastham-Anderson for morphometric analysis of the intestines, Y. Shang for making mutant Notch1 expression plasmids, S. Seshagiri for MT-3 sequencing, E. Quan for initial work with T-ALL lines, S. Chaudhuri for cloning and antibody characterization, and G. Plowman for insights and guidance. We appreciate the important contributions of F. de Sauvage, who helped initiate this collaborative project and provided guidance throughout. The Advanced Light Source and Berkeley Center for Structural Biology are supported by the Department of Energy, National Institutes of Health, and the National Institute of General Medical Sciences.

Author Contributions Y.W., Y.C. and S.S. generated the phage display antibodies and performed the in vitro binding experiments. G.P.d.L. purified and crystallized the NRR1-Fab complex. S.G.H. solved and analysed the structure, made the structure figures and wrote the corresponding section of the paper, D.F. and R.V. performed the MT-3 xenograft experiment, X.W. performed the Calu- 6 and HM7 xenograft experiments, J.R. performed the HUVEC experiments and M.Y. supervised these experiments; Ji.Z. and C.A.C. analysed intestinal pathology; C.C.-H., L.C. and T.J.H. performed the experiments characterizing antibody activity in vitro and in vivo, C.C.-H. also analysed CD31 staining in the Calu- 6 model, L.C. also analysed signalling from mutant receptors, T.J.H. also analysed T-ALL growth, including the HPB-ALL xenograft, L.C. and A.S. analysed T-ALL growth in vitro, G.J.D. performed the domain swap experiments, D.S.-R. performed the neonate retina experiments and R.J.W. supervised these experiments; Je.Z. purified and characterized antigens, R.C. developed in vitro signalling assays, P.H. developed cell-binding assays and L.K. supervised the work at Exelixis. C.W.S. supervised the experiments and wrote the paper.

Author Information Coordinates for the co-crystal structure have been assigned pdb accession code 3L95. Reprints and permissions information is available at www.nature.com/reprints. The authors declare competing financial interests: details accompany the full-text HTML version of the paper at www.nature.com/ nature. Correspondence and requests for materials should be addressed to C.W.S. (csiebel@gene.com). 


\section{METHODS}

Antibody generation. Human phage antibody libraries with synthetic diversities in the selected complementary determining regions ( $\mathrm{H} 1, \mathrm{H} 2, \mathrm{H} 3, \mathrm{~L} 3)$, mimicking the natural diversity of the human IgG repertoire, were used for panning. Fab fragments were displayed bivalently on the surface of M13 bacteriophage particles ${ }^{31}$. NRR fragments were expressed as secreted proteins fused to epitope tags (Flag or $6 \times$ His) using the baculovirus expression vector system or $293 \mathrm{~T}$ cells, purified to $>90 \%$ purity using affinity chromatography and tested for lack of aggregation using light scattering. The sequences of the NRR antigens were as follows: FlagHuman-Notch1-NRR-6×His, KDDDDKGSGVINGCKGKPCKNGGTCAVAS NTARGFICKCPAGFEGATCENDARTCGSLRCLNGGTCISGPRSPTCLCLGPF TGPECQFPASSPCLGGNPCYNQGTCEPTSESPFYRCLCPAKFNGLLCHILDY SFGGGAGRDIPPPLIEEACELPECQEDAGNKVCSLQCNNHACGWDGGDCS LNFNDPWKNCTQSLQCWKYFSDGHCDSQCNSAGCLFDGFDCQRAEGQC NPLYDQYCKDHFSDGHCDQGCNSAECEWDGLDCAEHVPERLAAGTLVVV VLMPPEQLRNSSFHFLRELSRVLHTNVVFKRDAHGQQMIFPYYGREEELRK HPIKRAAEGWAAPDALLGQVKASLLPGGSEGGRRRRELDPMDVRGSIVYLE IDNRQCVQASSQCFQSATDVAAFLGALASLGSLNIPYKIEAVQSETVEPPPPA QEFGLVPRGSGHHHHHH; Flag-Mouse-Notch1-NRR-6×His, KDYKDDDD KLEVINGCRGKPCKNGGVCAVASNTARGFICRCPAGFEGATCENDARTCG SLRCLNGGTCISGPRSPTCLCLGSFTGPECQFPASSPCVGSNPCYNQGTCEPT SENPFYRCLCPAKFNGLCHILDYSFTGAGRDIPPPQIEEACELPECQVDAGN KVCNLQCNNHACGWDGGDCSLNFNDPWKNCTQSLQCWKYFSDGHCDS QCNSAGCLFDGFDCQLTEGQCNPLYDQYCKDHFSDGHCDQGCNAECEW DGLDCAEVPERLAAGTLVLVVLLPPDQLRNNSFHFLRELSHVLHTNVVFKR DAQGQQMIFPYYGHEEELRKHPIKRSTVGWATSSLLPGTSGGRQRRELDP MDIRGSIVYLEIDNRQCVQSSQCFQSATDVAAFGALASLGSLNIPYKIEAVKS EPVEPPLPSQGSGHHHHHH; Flag-Human-Notch2-NRR-6×His, KDDDDK GSGDVCPQMPCLNGGTCAVASNMPDGFICRCPPGFSGARCQSSCGQVKC RKGEQCVHTASGPRCFCPSPRDCESGCASSPCQHGGSCHPQRQPPYYSCQ CAPPFSGSRCELYTAPPSTPPATCLSQYCADKARDGVCDEACNSHACQWD GGDCSLTMENPWANCSSPLPCWDYINNQCDELCNTVECLFDNFECQGNS KTCKYDKYCADHFKDNHCNQGCNSEECGWDGLDCAADQPENLAEGTLV IVVLMPPEQLLQDARSFLRALGTLLHTNLRIKRDSQGELMVYPYYGEKSAAM KKQRMTRRSLPGEQEQEVAGSKVFLEIDNRQCVQDSDHCFKNTDAAAALLA SHAIQGTLSYPLVSVVSESLTPERTEFGLVPRGSGHHHHHH; Mouse-Notch2NRR-Flag, ADVCPQKPCLNGGTCAVASNMPDGFICRCPPGFSGARCQSSCGQ VKCRRGEQCIHTDSGPRCFCLNPKDCESGCASNPCQHGGTCYPQRQPPHYS CRCPPSFGGSHCELYTAPTSTPPATCQSQYCADKARDGICDEACNSHACQW DGGDCSLTMEDPWANCTSTLRCWEYINNQCDEQCNTAECLFDNFECQRN SKTCKYDKYCADHFKDNHCDQGCNSEECGWDGLDCASDQPENLAEGTLII VVLLPPEQLLQDSRSFLRALGTLLHTNLRIKQDSQGALMVYPYFGEKSAAMK KQKMTRRSLPEEQEQEQEVIGSKIFLEIDNRQCVQDSDQCFKNTDAAAALLA SHAIQGTLSYPLVSVFSELESPRNARRAGSGDYKDDDDKENLYFQ.

Nunc 96-well MaxiSorp immunoplates were coated overnight at $4{ }^{\circ} \mathrm{C}$ with NRR1 or NRR2 protein $\left(10 \mu \mathrm{g} \mathrm{ml}^{-1}\right)$ and blocked for $1 \mathrm{~h}$ with PBST buffer (PBS, $0.05 \%$ Tween 20) plus 1\% BSA. The libraries were added and incubated overnight at room temperature. Plates were washed with PBST buffer, bound phage were eluted with $50 \mathrm{mM} \mathrm{HCl}$ and $500 \mathrm{mM} \mathrm{NaCl}$ for $30 \mathrm{~min}$, and the eluate was neutralized with an equal volume of $1 \mathrm{M}$ Tris base. Recovered phage were amplified using Escherichia coli XL-1 blue cells. During subsequent selection rounds, the binding time was decreased to $2 \mathrm{~h}$ as the stringency of plate washing increased $^{32}$. Phage antibodies that bound to both human and murine forms of the targeted NRRs were identified by ELISA and DNA sequencing. Antibody clones were reformatted to express full-length IgGs by cloning the light chain $\left(\mathrm{V}_{\mathrm{L}}\right)$ and heavy chain $\left(\mathrm{V}_{\mathrm{H}}\right)$ regions into LPG3 and LPG4 vectors, respectively. Antibodies were transiently expressed in mammalian cells and purified using protein $\mathrm{A}^{33}$.

SPR with a BIAcore-3000 instrument was used to determine antibody binding affinities $^{32}$. For Notch1, anti-NRR1 was coated directly on CM5 biosensor chips to achieve approximately 400 response units (RU), and purified human or murine NRR1 was injected; for Notch2, purified human $(6 \times$ His epitope tag) or mouse (Fc epitope tag) NRR2 was coated on the chips, and anti-NRR2 was injected. Injections were done in PBST buffer at $25^{\circ} \mathrm{C}$ with a flow rate of $30 \mu \mathrm{lmin}{ }^{-1}$. Association and dissociation rates were calculated using a simple one-one Langmuir binding model (BIAcore Evaluation Software version 3.2).

Phagemids displaying monovalent $\mathrm{Fab}^{31}$ served as the library template for grafting $\mathrm{V}_{\mathrm{L}}$ and $\mathrm{V}_{\mathrm{H}}$ variable domains for affinity maturation using a soft randomization strategy ${ }^{32}$. Stop codons were incorporated in CDR-L3. Three combinations of CDR loops (H1/H2/L3, H3/L3 or L1/L2/L3) were selected for randomization. Affinity-matured clones were selected by sorting against NRR protein, first on plates (one round) and then in solution (four rounds) ${ }^{31}$. A highthroughput, single-point, competitive phage ELISA was used to screen rapidly for high-affinity clones ${ }^{34}$.
ELISA. Serial dilutions of antibodies were incubated for $1 \mathrm{~h}$ at room temperature on 96-well Maxisorp plates coated with $1 \mu \mathrm{g}$ of purified human or mouse NRR proteins, each tagged with $6 \times$ His except for human NRR2, which was tagged with human Fc. The plates were washed, and bound antibodies were detected with anti-human antibody HRP conjugates. The signal was developed with one component TMB substrate and measured at $630 \mathrm{~nm}$. Data were plotted using a four-parameter nonlinear regression curve-fitting program (KaleidaGraph, Synergy Software).

Notch reporter assays. NIH-3T3 cells stably transfected with Notch1 or transiently transfected with Notch expression plasmids were co-transfected with a Notch-responsive TP-1 (12X CSL) firefly luciferase reporter and a constitutively expressed Renilla luciferase reporter (pRL-CMV, Promega) to control for transfection efficiency. Antibodies, $N$-[N-(3,5-difluorophenylacetyl)-L-alanyl $]-S$ phenylglycine tert-butyl ester (DAPT) $(5 \mu \mathrm{M})$ or compound E $(1 \mu \mathrm{M})$ (both from EMD) were added together with the ligand-expressing cells (NIH-3T3 cells stably transfected with Jag1 under control of the CMV promoter) 6-18 h after transfection. Luciferase activities were measured after $20 \mathrm{~h}$ of co-culture (Promega, Dual Glo Luciferase). Typically, four to eight replicates were analysed for each condition, and values were expressed as relative luciferase units (firefly signal divided by the Renilla signal). For the Notch2 signalling assay, U87MG cells (which predominantly express Notch2 as well as a low level of Notch1) were used in place of NIH3T3-Notch1 cells. As noted in the text or figure legends, the NIH-3T3-based assay was also performed in a 'transient' format in which an expression plasmid encoding the Notch receptor to be tested was transiently transfected together with the luciferase reporter plasmids.

$\mathrm{T}$ cell and marginal zone $\mathbf{B}$ cell analysis. BALB/c mice (Jackson Labs) at 12 weeks old were injected intraperitoneally every 4 days for 2 weeks with $5 \mathrm{mg} \mathrm{kg}^{-1}$ of anti-gD, anti-NRR1 or anti-NRR2 or $10 \mathrm{mg} \mathrm{kg}^{-1}$ of LT $\beta R-F c$. Thymocytes were stained with anti-CD8-PE-Cy5 and anti-CD4-APC (BD Biosciences) $)^{35,36}$ and splenocytes with anti-B220-APC, anti-CD5-PerCP, antiCD23-PE and anti-CD21-FITC (BD Biosciences) ${ }^{13}$, and flow cytometry was performed using a FACSCalibur (BD Biosciences) or a LSRII (BD Biosciences), with FACSDiva (BD Biosciences) and FlowJo (Tree Star) software. Co-crystallization of Notch1 NRR and Fab. The Fab fragment of anti-NRR1 was expressed in E. coli, purified using Protein G-sepharose, and eluted with $0.58 \%$ acetic acid. Fab-containing fractions were then purified using a SP HiTrap column (GE Healthcare) with $20 \mathrm{mM}$ MES pH 5.5 and a $\mathrm{NaCl}$ gradient. Human Notch NRR1 (residues A1449-P1729 with deletion of residues R1623-M1670 in the S1 loop) with the addition of a C-terminal $6 \times$ His tag was expressed in SF9 insect cells. NRR1 containing medium was separated from cells by centrifugation and purified using a $10 \mathrm{ml}$ Ni-NTA Superflow (Qiagen) column. NRR1 was eluted with $500 \mathrm{mM} \mathrm{NaCl}$ and $300 \mathrm{mM}$ imidazole in $20 \mathrm{mM}$ Tris, pH 8.0. Fractions containing the NRR1 were pooled, and NRR1 was further purified by size exclusion chromatography (S-75, Pharmacia). NRR1-Fab complexes were prepared with a molar excess of Fab. The protein complex was purified using sizing column chromatography (S-200, Pharmacia) in $150 \mathrm{mM} \mathrm{NaCl}$, $20 \mathrm{mM}$ Tris-Bis, pH 6.5. Fractions containing complex were pooled and concentrated to approximately $6 \mathrm{mg} \mathrm{ml}^{-1}$ for crystallization trials. Crystals grew in sitting drops from a 1:1 mixture of protein and well solution $(300 \mathrm{mM}$ diammonium sulphate, 20\% polyethylene glycol $5000 \mathrm{MME}, 100 \mathrm{mM}$ Tris $\mathrm{pH}$ 7.5) at $19^{\circ} \mathrm{C}$. Microseeding was used to control nucleation and crystal size. Crystals $(0.2 \mathrm{~mm} \times 0.15 \mathrm{~mm} \times 0.1 \mathrm{~mm})$ were cryo-protected in Paratone-N (Qiagen). Crystallographic data were collected at beamline 5.0.2 of the Advanced Light Source (Supplementary Table 1) and processed with XDS. The structure was solved by molecular replacement with the program PHASER (CCP4) using the structure of human Notch 2 NRR (PDB code 2OO4) and a variant of the humanized Fab 4D5 (ref. 37) as a search model followed by refinement with REFMAC5 (CCP4). NCS restraints were applied on the light chain Fv, heavy chain Fv, light chain constant domain, heavy chain constant domain and NRR1 residues 1461-1726 throughout refinement. The final model has excellent geometry with $99.2 \%$ of all residues in the most favoured or additional allowed regions of a Ramachandran plot and only $0.8 \%$ in either the generously allowed or disallowed regions. Structure figures were made with PyMOL (www.pymol.org).

Cell cycle, proliferation and apoptosis assays. Cells were plated at $5 \times 10^{5} \mathrm{ml}^{-1}$ in growth medium and treated with DAPT or the equivalent volume of vehicle (dimethyl sulfoxide, DMSO), $10 \mu \mathrm{g} \mathrm{ml}^{-1}$ anti-gD (isotype control antibody) or $10 \mu \mathrm{g} \mathrm{ml}^{-1}$ anti-NRR1. Cells were split to $5 \times 10^{5} \mathrm{ml}^{-1}$ every $2-3$ days and retreated with drugs. After 7-8 days in culture, cells were fixed in $70 \%$ ethanol and stained with propidium iodide. DNA content was determined by flow cytometry and cell cycle analysis was performed using ModFit software (Verity).

For analysis of proliferation using Ki-67, T-ALL cells were maintained in Iscove's modified Dulbecco's medium supplemented with $8 \%$ fetal calf serum (FCS, Sigma). Cultures were inoculated with $1 \times 10^{6}$ cells and treated for 9 days 
with $5 \mu \mathrm{M}$ DAPT or an equivalent volume of DMSO, $10 \mu \mathrm{g} \mathrm{ml}^{-1}$ anti-gD or $10 \mu \mathrm{g} \mathrm{ml}^{-1}$ anti-NRR1; at days 4 and 7, cells were split 1:4 and 2:5, respectively. Intracellular staining using anti-Ki-67-FITC (BD Biosciences) was performed using the Cytofix/Cytoperm Fixation/Permeabilization kit (BD Biosciences) according to the manufacturer's instructions.

To analyse MT- 3 growth in vitro, $1 \times 10^{4}$ cells were plated in wells of a 96-well plate in RPMI 1640 with 10\% FCS and allowed to attach overnight. Cultures were then grown without FCS for 5 hours before the medium was changed to RPMI 1640 with 2.5\% FCS and drugs were added. Medium was refreshed every 2-3 days. Viability was assayed after 1 week using CellTiter-Glo (Promega).

Immunoblotting. T-ALL cell lines were treated with $5 \mu \mathrm{M}$ DAPT or an equivalent volume of DMSO, $50 \mu \mathrm{g} \mathrm{ml}^{-1}$ anti-gD antibody, or 10 or $50 \mu \mathrm{g} \mathrm{ml}^{-1}$ anti-NRR1 antibody for $48 \mathrm{~h}$, with the addition of $10 \mu \mathrm{M}$ MG132 for the last $3 \mathrm{~h}$. Cells were lysed in $0.2 \%$ NP-40, $10 \mathrm{mM}$ HEPES pH 7.9, $10 \mathrm{mM} \mathrm{KCl,} 1 \mathrm{mM}$ EDTA, 10\% glycerol, and $1 \times$ HALT protease inhibitor cocktail (Pierce). Nuclei were recovered by centrifugation and subsequently lysed in $1 \times$ RIPA buffer with protease inhibitor cocktail. Immunoblotting was performed using anti-Notch1 V1744 and anti-CREB antibodies from Cell Signaling Technologies.

In vivo tumour studies. Animal studies were conducted in accordance with the Guide for the Care and Use of Laboratory Animals, published by the National Academy Press (2006). The Institutional Animal Care and Use Committee (IACUC) of Genentech approved all protocols. HPB-ALL cells $\left(20 \times 10^{6}\right)$, cultured in Iscove's modified Dulbecco's medium with 8\% FCS (Sigma), were diluted in $200 \mu \mathrm{l} 50 \%$ Matrigel (BD Biosciences)/50\% PBS and implanted subcutaneously in $\gamma c^{-1-} \times$ Rag $^{-/-}$mice $^{38}$. When tumours reached $500 \mathrm{~mm}^{3}$, mice were randomized into groups of equal average tumour volume, and treated with intraperitoneal doses of antibody. Tumour volumes were measured in two dimensions (length and width) using UltraCal-IV calipers (Model 54-10-111, Fred V. Fowler Company) and calculated using the formula: tumour volume $=($ length $\times$ width $\left.^{2}\right) \times 0.5$.

MT-3 cells, obtained from Deutsche Sammlung von Mikroorganismen und Zellkulturen (DSMZ), were cultured in RPMI 1640 media plus 1\% L-glutamine with $10 \%$ FCS (Invitrogen). Cells $\left(5 \times 10^{6}\right.$ in $\left.0.2 \mathrm{ml}\right)$ were implanted in the right flank of 8 -week-old female NCR nude mice (Taconic Farms). When tumours reached $82-227 \mathrm{~mm}^{3}$, mice were treated as described above.

Calu-6 (human anaplastic carcinoma, probably lung) and HM7 (human colon carcinoma) tumour cell lines were grown in Ham's F12, low glucose DMEM 1:1 supplemented with 10\% v/v FCS, $1 \% \mathrm{v} / \mathrm{v}$ penicillin/streptomycin, $2 \mathrm{mM}$ L-glutamine and $1 \mu \mathrm{g} \mathrm{ml}^{-1}$ Fungizone (Invitrogen). Cells were suspended at a concentration of $1 \times 10^{8}$ or $1 \times 10^{9}$ cells ml $^{-1}$ and injected $(100 \mu \mathrm{l}$ per mouse) subcutaneously into the dorsal flank of Balb/c nude mice (Harlan Sprague Dawley). When tumours reached a volume of $250-300 \mathrm{~mm}^{3}$, cohorts of ten mice were randomly divided into groups. The transplanted tumours were measured twice weekly along the longest axis and the perpendicular axis, and tumour volumes were calculated. The mean tumour volumes were compared using Dunnett's $t$-test implemented in the JMPTM Statistical Analysis System (version 5.1 for Windows; SAS Institute), at a level of $P<0.05$. Tumours were sectioned by cryostat to $7 \mu \mathrm{m}$, fixed with acetone and stained with DAPI (Invitrogen), hamster anti-CD31 (Serotec) and an anti-hamster Cy3 secondary antibody (Jackson ImmunoResearch). Slides were mounted with Fluorescent Mounting Medium (Dako). Images were taken with a Zeiss Axioskop2 microscope and analysed by ImageJ for area of DAPI stain and Cy3 staining. To normalize for cell number, the values for $\mathrm{Cy} 3$ stain were divided by the corresponding areas of DAPI stain. The ratio determined for the anti-ragweed control was set at a value of 1 .

Neonatal retinal assay for angiogenesis. As described ${ }^{21}$, CD1 neonates (Charles River) were injected intraperitoneally at 1 and 3 days after birth with either $10 \mathrm{mg} \mathrm{kg}^{-1}$ of ragweed control antibody or $20 \mathrm{mg} \mathrm{kg}^{-1}$ of anti-NRR1. Retinas were harvested 2 days later and fixed with $4 \%$ paraformaldehyde. After blocking with $5 \%$ BSA, $0.5 \%$ Triton X-100 for $1 \mathrm{~h}$, followed by $1 \mathrm{M}$ sodium citrate for $10 \mathrm{~min}$, biotinylated isolectin B4 (Sigma) and anti-Ki-67 antibody (NeoMarkers) were added for incubation at $4{ }^{\circ} \mathrm{C}$ overnight. Retinas were subsequently washed and stained with streptavidin-Alexa 488 and Cy3-conjugated goat anti-rabbit in $1 \% \mathrm{BSA}, 0.5 \%$ Triton $\mathrm{X}-100$, before mounting and imaging using an epifluorescence microscope.

Histology and immunohistochemistry of mouse intestine tissue. BALB/c mice (Jackson Labs) at 12 weeks old were injected intraperitoneally twice per week, and small intestine samples were harvested on day 12. Formalin-fixed and paraffin-embedded tissues were sectioned at $3 \mu \mathrm{m}$ thickness. Histochemical identification of intestinal cell types was performed with Alcian blue as recommended by the manufacturer (PolyScientific). For anti-Ki-67 staining, sections were pretreated with Target Retrieval Solution (S1700, DAKO), and incubated with rabbit anti-Ki-67 (1:200, clone SP6, Neomarkers). Secondary goat antirabbit at $7.5 \mu \mathrm{g} \mathrm{ml}^{-1}$ (Vector labs) was detected with the Vectastain ABC Elite Kit (Vector labs). Ki-67-stained sections were counterstained with Mayer's haematoxylin. Crypt areas of at least $100,000 \mu \mathrm{m}^{2}$, which contained at least 1,000 crypt cells, were analysed to determine the proliferative index, expressed as the percentages of Ki-67-positive crypt epithelial cells in the crypt areas examined. For anti-lysozyme staining, sections were processed on the Discovery XT platform (Ventana Medical Systems) using CClm epitope recovery conditions, OmniMap-rabbit detection and Ventana haematoxylin II/with blueing counterstain. For HES-1 staining, anti-rat HES-1 (clone NM1, MBL International) was followed by TSA-HRP.

31. Lee, C. V. et al. High-affinity human antibodies from phage-displayed synthetic Fab libraries with a single framework scaffold. J. Mol. Biol. 340, 1073-1093 (2004).

32. Liang, W.-C. et al. Function blocking antibodies to Neuropilin-1 generated from a designed human synthetic antibody phage library. J. Mol. Biol. 366, 815-829 (2007).

33. Carter, P. et al. Humanization of an anti-p185HER2 antibody for human cancer therapy. Proc. Natl Acad. Sci. USA 89, 4285-4289 (1992).

34. Sidhu, S. S. et al. Phage-displayed antibody libraries of synthetic heavy chain complementarity determining regions. J. Mol. Biol. 338, 299-310 (2004).

35. Hagenbeek, T. J. \& Spits, H. T-cell lymphomas in T-cell-specific Pten-deficient mice originate in the thymus. Leukemia 22, 608-619 (2008).

36. Hagenbeek, T. J. et al. The loss of PTEN allows TCR $\alpha \beta$ lineage thymocytes to bypass IL-7 and pre-TCR-mediated signaling. J. Exp. Med. 200, 883-894 (2004).

37. Eigenbrot, C., Randal, M., Presta, L., Carter, P. \& Kossiakoff, A. A. X-ray structures of the antigen-binding domains from three variants of humanized anti-p185HER2 antibody 4D5 and comparison with molecular modeling. J. Mol. Biol. 229, 969-995 (1993).

38. Kirberg, J., Berns, A. \& Boehmer, H. V. Peripheral T cell survival requires continual ligation of the $T$ cell receptor to major histocompatibility complex-encoded molecules. J. Exp. Med. 186, 1269-1275 (1997). 